\title{
Review of Roundabout Design Standards and the Development of a Roundabout Design Guideline for Sri Lanka
}

\author{
E.M.C.B. Ekanayake and W.K. Mampearachchi
}

\begin{abstract}
In Sri Lanka, the geometry of roundabouts has a considerable influence on their operation. The increase in road traffic and the large number of long vehicles that ply on the roads have contributed to the malfunctioning of some of these roundabouts. The objectives of this study were to review the roundabout design guidelines, identify issues in the existing roundabouts and prepare a roundabout design guideline appropriate for Sri Lanka. Twenty four roundabouts located in some of the major cities were selected for the study. The design parameters of the geometries of the selected roundabouts were compared with those recommended in five major design guidelines. Data on the main geometric parameters of each roundabout were collected through field measurements and calibrated satellite images. The dimensions and the design parameters of these roundabouts were compared with those stated in a few international roundabout guidelines. A swept path analysis was carried out on selected roundabout layouts for single unit trucks to determine the adequacy of their entry widths, circulation widths, exit widths and operational speeds. The entry radiiwere higher than those recommended in the international standards. The design parameters of the existing roundabouts that required improvements were identified and suitable values for the selected design parameters have been proposed. Most of the roundabouts meet the minimum requirements specified in the international guidelines for the centre island diameter (100\%), circulation width (92\%), and exit radius $(92 \%)$.
\end{abstract}

Keywords: $\quad$ Design Parameters, Guidelines, Roundabouts

\section{Introduction}

\subsection{General}

Since the end of the 30 year old civil war, Sri Lanka has been undergoing rapid development. This has resulted in sudden peaks of accessibility and mobility for the people which together have become a major factor to be considered in transportation and highway design engineering. With the development of the road network, the number of trips generated have increased. So, the local authorities have developed a tendency to implement traffic controlling measures through the introduction of signs at junctions, roundabouts, intersections, signal lights etc. Roundabouts have been used frequently in urban areas like Colombo, Gampaha, Anuradhapura and Galle in which there is a higher degree of mobility of people.

\subsection{Background}

Roundabouts are common in urban areas of Sri Lanka. They have become useful in those intersections which have capacity/delay issues or where traffic signals have not been provided even though warranted, in four way stop intersections etc. In Sri Lanka, there are several locations that have been identified as inappropriate sites for roundabouts considering the following factors:

1. Inability to provide a satisfactory geometric design

2. The better level of service that can be obtained from an interconnecting signal system

3. Desirability of controlling traffic via signal timings

4. Possibility of employing peak period reversible lanes

5. Possibility of queuing from a nearby signal becoming a problem when the roundabout is close to an existing signal

6. Inability to balance the incoming vehicles from different approaches

Eng. E.M.C.B. Ekanayake, CEng, MIE(Sri Lanka), B.Sc. Eng.(Peradeniya), P.G Dip(Structural Eng Design), M.Eng.(Highway and Traffic Eng), MCIHT(UK), Highway Design Engineer, Consulting Engineers and Architects Associated (Pvt.) Ltd.

Email:cbek.sl@gmail.com

Eng. (Prof.) W.K. Mampearachchi, CEng., MIE(Sri Lanka), B.Sc. Eng.(Moratuwa), MSCE (South Florida), Ph.D.(Florida), Professor of Civil Engineering, Department of Civil Engineering, University of Moratuwa.

Email:wk.mampearachchi@gmail.com 
The geometry of a roundabout is very important if the roundabout is to function properly. Some of the roundabouts (constructed) in Sri Lanka are underperforming causing accidents and delays. Sri Lanka does not have a design guideline of its own that can be followed during the geometric design stage of the roundabouts. Hence, it is advisable to check the design parameters of a few selected roundabouts in Sri Lanka against those mentioned in some of the international design guidelines.

It is also timely to identify the roundabouts which need geometric improvements and propose values for their design parameters by developing a design guideline for Sri Lanka.

\section{Literature Review}

\section{$2.1 \quad$ Introduction}

A roundabout is a type of intersection in which road traffic flows almost continuously in one direction around a central island. The single greatest benefit of roundabouts is that they eliminate perpendicular / T-bone crashes. Their other benefits include the reduction of driver confusion associated with perpendicular junctions and the reduction of queuing associated with traffic lights. They allow Uturns within the normal flow of traffic, which often are not possible at other forms of junctions [1].

Before roundabouts came into place, there had been circular junctions which included the Bath Circus world heritage site completed in 1768and the Place de l'Étoile around the Arc de Triomphe in Paris inaugurated in 1907. The operating and entry characteristics of these circles differ considerably from those of modern roundabouts. The first British circular junction was built in the Letchworth Garden City in 1909. In the early twentieth century, its centre was intended partly as a refuge island for pedestrians [2].

Roundabouts are now common all over the world. Half of the world's roundabouts are in France (more than 30,000 as of 2008) [3]. The following locations have been identified as suitable for roundabouts [4].

1. High accident locations (left turns with the right hand driving rule or right angle accidents in particular).

2. Intersections with capacity/delay problems

3. Intersections for which traffic signals have been requested though not warranted.
4. Intersections warranting traffic signals

5. 4-way stop intersections

\subsection{Types of Roundabouts}

\subsubsection{Conventional Roundabouts}

A conventional roundabout is defined as one which is circular in shape and in which all vehicles circulate clockwise around a central island. This type of roundabout is shown in Figure 1.

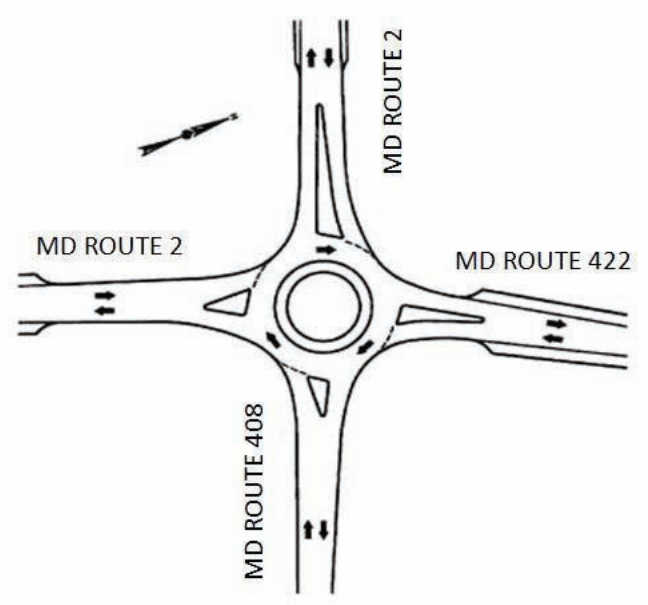

Figure 1 - Conventional roundabout

\subsubsection{Mini-Roundabout}

A mini-roundabout is defined as a roundabout with a fully mountable central island. Miniroundabouts should be restricted to low volume, low speed roadways with prohibited or restricted truck movements.

\subsubsection{Raindrop Roundabouts}

Raindrop roundabouts do not form a complete circle and have a raindrop or teardrop shape. They provide free-flowing left turns to the onramps and eliminate the need for turn signals and lanes. They also prevent queuing on narrow two-lane bridges.

\subsubsection{Turbo Roundabouts}

Turbo roundabouts provide a forced spiralling flow of traffic, requiring motorists to choose their direction of travel before entering the roundabout. By eliminating many conflicting paths and choices at the roundabout itself, traffic safety as well as speed and capacity is increased. A turbo roundabout will allow Uturns only from two directions. 


\subsubsection{Inscribed Circle Diameter}

The inscribed circle diameter is the distance across the circle inscribed by the outer curb (or edge) of the circulatory roadway. It is determined based on a number of design objectives. The designer often has to experiment with varying diameters before determining the optimal value for a given location. [5] The maximum roundabout diameter should be limited to $200 \mathrm{~m}$. Larger diameters will encourage high circulating speeds and may encourage wrong way movements [6].

\subsubsection{Entry Width}

The entry width is the most important determinant of a roundabout's capacity. The capacity of an approach does not depend on the number of entering lanes alone, but also on the total width of the entry. The entry width is measured along a line perpendicular to the right curb line from the point at which the yield line intersects with the left edge of the travelled-way, to the right edge of the travelledway[5].

\subsubsection{Circulatory Roadway Width}

The required width of the circulatory roadway is determined from the width of the entries and the turning requirements of the design vehicle. In general, it should always be at least as wide as the maximum entry and should remain constant throughout the roundabout [5].

\subsubsection{Central Island}

The central island of a roundabout is the raised, non-traversable area encompassed by the circulatory roadway. This area may also include a traversable apron. The island is generally landscaped for aesthetic reasons and to make it easily recognised by drivers as they approach it. In general, the central island should be circular in shape. A circular-shaped central island with a constant-radius circulatory roadway helps to promote constant speeds around the central island. Oval or irregular shapes, on the other hand, are more difficult to drive around and can promote higher speeds along the straight sections and lower speeds along the arcs of the oval. This speed differential may make it harder for entering vehicles to judge the speed and acceptability of gaps in the circulatory traffic stream.

\subsubsection{Entry Curves}

The entry curve is a set of one or more curves along the left curb of the entry roadway leading to the circulatory roadway. The primary objective of selecting an appropriate radius for the entry curve is to achieve speed objectives. The entry radius should first produce an appropriate design speed on the fastest vehicular path. Secondly, it should desirably result in an entry path radius equal to or less than the circulating path radius [5].

\subsubsection{Exit Curves}

Exit curves usually have larger radii than entry curves in order to minimize the congestion at the exit points. This, however, is balanced by the need to maintain low speeds at pedestrian crossings at the exit points. The exit curve should produce an exit path radius which should not be smaller than the circulating path radius as otherwise the speeds of the vehicles will be not slow enough to negotiate the exit geometry and the vehicles may crash into the splitter island or into oncoming traffic in the adjacent approach lane. Likewise, the exit path radius should not be significantly higher than the circulating path radius if low speeds are to be ensured at the downstream pedestrian crossings.

\subsubsection{Flare Length}

The theoretical capacity is very sensitive to changes in the flare length. Flare should be developed uniformly, without any sharp changes in the angle, if it is to be practically effective. The minimum value for the flare is $5 \mathrm{~m}$ for an urban area, and $15 \mathrm{~m}$ for a rural area. The upper limit should be 40m [7].

\subsubsection{Entry Path Deflection}

One of the most important safety checks at a roundabout is the vehicle path deflection when the vehicles enter. It is necessary to prevent excessive speeds at the roundabout. For design purposes, the vehicle entry path should be such that the radius of the tightest curve on the entry path does not exceed $100 \mathrm{~m}$ [7]. An appropriate radius on the entry curve will encourage the drivers to slow down before reaching the roundabout [6].

\subsubsection{Entry Angle}

The entry angle is a geometric proxy for the conflict angle between the entering and circulating streams. The relationship between the entry angle and the entry capacity is an inverse one in that as the angle increases, the capacity will decrease slightly. However, care should be taken in the choice of the entry angle, because angles which are too high and those 
which are too low may both lead to an increased potential for accidents[7].

\subsubsection{Cross Fall and Drainage}

A super elevation will not be required on the circulating pavements of the roundabouts irrespective of their size, whereas a cross fall will be required to enable surface water to drain off effectively. The cross fall on the circulating pavement can be inwards (towards the central island), with a normal crown profile, or outwards. An inward cross fall may be appropriate for very large roundabouts where circulating speeds are high, but elsewhere the fall should normally be normal crown type or outwards.

\subsubsection{Vertical Consideration}

The design elements pertaining to the vertical alignment of roundabouts include profiles, super elevation, approach and grades.

- Super Elevation

As a general practice, a cross slope of $2 \%$ away from the central island should be used for a circulatory roadway. This technique of sloping outwards is recommended considering the following facts:

- Improved safety available when the elevation of the central island has been raised to improve its visibility

- Lowering of circulating speeds

- Minimizing of breaks in the cross slopes of the entrance and exit lanes

- Enabling of the surface water to drain off to the outside of the roundabout

\section{$2.4 \quad$ Roundabout Guidelines}

The following international guidelines have been considered in this study:

1. US DOT guidelines

2. Austroads guidelines

3. UK guidelines

4. Dubai guidelines

5. Oman guidelines

A summary of the above mentioned guidelines is presented in Table 1.

Table 1 - Summary of guidelines

\begin{tabular}{|l|c|c|c|c|c|}
\hline Roundabout & Austroads & AASHTO & DMRB & DUBAI & OMAN \\
\hline $\begin{array}{l}\text { Inscribed } \\
\text { circle } \\
\text { Diameter, } \mathrm{m}\end{array}$ & $25-37$ & $25-30$ & $\min 28$ & $\min 29$ & $\min 28$ \\
\hline $\begin{array}{l}\text { Center } \\
\text { Island } \\
\text { Diameter, } \mathrm{m}\end{array}$ & 10 & $\begin{array}{c}\text { based on } \\
\text { design } \\
\text { vehicle }\end{array}$ & $\min 4$ & $\min 4$ & $\min 4$ \\
\hline $\begin{array}{l}\text { Circulation } \\
\text { Width single } \\
\text { Lane, } \mathrm{m}\end{array}$ & 7.6 & $\begin{array}{c}(1-1.2)^{*} \\
\text { MEW }\end{array}$ & $\begin{array}{c}(1-1.2)^{*} \\
\text { MEW }\end{array}$ & $\begin{array}{c}(1-1.2)^{*} \\
\text { MEW }\end{array}$ & $\begin{array}{c}(1-1.2)^{*} \\
\text { MEW }\end{array}$ \\
\hline $\begin{array}{l}\text { Entry } \\
\text { Radius, } \mathrm{m}\end{array}$ & Max 60 & $10-100$ & $10-100$ & $10-20$ & \begin{tabular}{c}
$10-100$ \\
\hline $\begin{array}{l}\text { Exit Radius, } \\
\mathrm{m}\end{array}$
\end{tabular} straight as \\
possible & $\begin{array}{c}\text { straight } \\
\text { as } \\
\text { possible }\end{array}$ & $20-100$ & $\begin{array}{c}(20- \\
200)\end{array}$ & $\begin{array}{c}\text { Exit } \mathrm{R} \\
>= \\
\text { Entry R }\end{array}$ \\
\hline
\end{tabular}

\begin{tabular}{|l|c|c|c|c|c|}
\hline $\begin{array}{l}\text { Entry width, } \\
\mathrm{m}\end{array}$ & 5 & $\min 6$ & $3-4.5$ & $6-15$ & $3-4.5$ \\
\hline $\begin{array}{l}\text { Exit width, } \\
\mathrm{m}\end{array}$ & 5 & $\begin{array}{c}\text { based on } \\
\text { exit curve } \\
\mathrm{R}\end{array}$ & $7-7.5$ & 7.3 & $7-7.5$ \\
\hline $\begin{array}{l}\text { Entry Angle, } \\
\text { degree }\end{array}$ & - & - & $20-60$ & $\begin{array}{c}20-60 \\
30 \mathrm{opt}\end{array}$ & $20-60$ \\
\hline $\begin{array}{l}\text { Approach } \\
\text { path radius, } \\
\mathrm{m}\end{array}$ & 100 & 100 & 100 & 100 & 100 \\
\hline
\end{tabular}

MEW- Maximum Entry Width

\section{Methodology}

The roundabouts (RA) selected for this study are some of the major roundabouts found in Sri Lanka. Their selection was based on the following:

- Being located in major cities with high traffic

- Being nodes for several major roads Being in cities which had many roundabouts with minimal restrictions from the surroundings for any modifications required

A detailed roundabout layout was developed making use of satellite images and collected field data. The design parameters that were extracted from the RA layouts were compared with the corresponding values recommended in the international design guidelines. A swept path analysis was carried out for a SU (Single Unit Truck) vehicle to check the adequacy of entry width, circulation width, exit width and operational speed of each of the roundabouts. The parameters that need to be improved in the existing roundabouts and the factors to be considered in developing a design guideline for Sri Lanka were thereafter identified.

\subsection{Identification of Suitable Roundabouts}

Roundabouts can be seen in many parts around the country. However, the roundabouts selected for the study had one or more of the following characteristics in that they were,

1. located in major cities with high vehicle capacity,

2. acting as nodes for a multitude of major roads or

3. located in cities which had many roundabouts withminimal restrictions from the surroundings for any modifications required.

Based on the above, twenty four (24) roundabouts located in Colombo, Panadura, Kalutara, Kurunegala and Anuradhapura were selected for the study.

The roundabouts in Colombo, Panadura and Kalutara were mainly of the high vehicle capacity type. The roundabouts selected from 
Colombo were only the most important ones such as the Borella roundabout, Lipton roundabout, Thalawathugoda roundabout and GalleFace roundabout. The roundabout located in the Kurunegala city was optimally located in that it had important connecting nodes as well as a high capacity. Anuradhapura is a city with a significant number of roundabouts. It also has ample space for the rehabilitation or widening of the roundabouts brought about by a design change.

\subsection{Roundabout Design Guidelines}

Many developed countries in the world such as USA, UK, Australia, France, Denmark, Oman, Dubai etc., have developed their own guidelines for the design of their roundabouts. These guidelines are also being followed by some of the other countries as well when they design their roundabouts.

\subsection{Development of the Roundabout Layout}

It was very costly to measure in a very short period all of the parameters of the roundabouts that were considered for the study and which were in highly populated urban areas. The following procedure was adopted when developing the roundabout layout:

1. Identification of a limited number of dimensions through field measurements

2. Calibration of satellite images

3. Validation of parameters

The roundabout diameter and the circulation width were measured using field data that was collected.

\subsubsection{Calibration of the Satellite Images}

The satellite images of the roundabouts selected for the study were obtained using satellite maps and there was special consideration given to the images that were clear and updated. Thereafter, the field measurements of the ICD (Inscribed Circle Diameter) were compared with those in the satellite image and the AutoCAD drawing image was calibrated to suit the field measurements.

\subsubsection{Validation of the Parameters}

The remaining field measurements were used to validate the calibrated roundabout image. Using AutoCAD, the remaining field measurements (entry width and the length of the splitter island) were compared with those of the calibrated roundabout image. If both values were same, the validation process was considered to be complete for the selected roundabouts. Validated roundabout layouts were then used to obtain some of the other parameters of the roundabouts. Following this, detailed roundabout layouts were drawnup using Auto CAD, to obtain the other roundabout parameters.

\subsection{Roundabout Parameters}

The definitions given to roundabout parameters in the widely used roundabout guidelines are mentioned in the literature. Roundabout parameters can be categorized in to three types as given below, based on the methods adopted to obtain them.

1. Parameters obtained through field measurements

2. Parameters extracted from validated roundabouts (satellite images).

3. Parameters derived using construction lines on AutoCAD drawings.

\subsubsection{Field Measurements}

These are the parameters that can be directly obtained from the roundabouts and which can be easily measured. Examples of such parameters are the island diameter, circulation width and splitter island width. They can be measured easily in a roundabout even with heavy traffic.

\subsubsection{Extracted Measurements}

Using direct measurements, a roundabout layout was drawn with the aid of satellite images. Using the corrected satellite images, the other important parameters given below, could also be extracted:

- Entry width

- Exit width

- Entry radius

- Exit radius

\subsubsection{Derived Parameters}

Using the updated satellite images, other important parameters of the roundabouts were derived by constructing on the layout the geometric features discussed in Section 2.3. These parameters are the,

- entry angle,

- exit angle and the

- approach path radius

\subsection{Design Vehicle}

Roundabouts should always be designed for the largest vehicle that can reasonably be anticipated in it which is called the design vehicle. For single-lane roundabouts, this may require the use of a mountable apron around 
the perimeter of the central island to provide the additional width needed for tracking the trailer wheels. At double-lane roundabouts, large vehicles may track across the whole width of the circulatory roadway when negotiating the roundabout. In Sri Lanka, the most frequent and the largest vehicle that will negotiate a roundabout is the single unit truck. In highway design practice, it is known as AASHTO SU vehicle. The details of the vehicle are shown in Figure 2. The swept path envelope of the AASHTO SU vehicle is shown in Figure 3. This vehicle will be used for the swept path analysis of the existing roundabouts to check whether the parameters of these roundabouts would ensure their satisfactory operation.

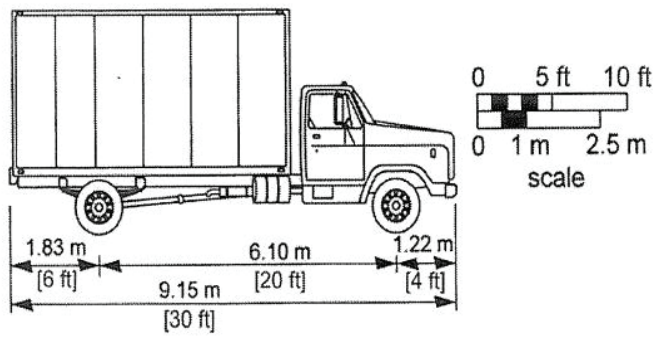

Figure 2 - Details of the design vehicle

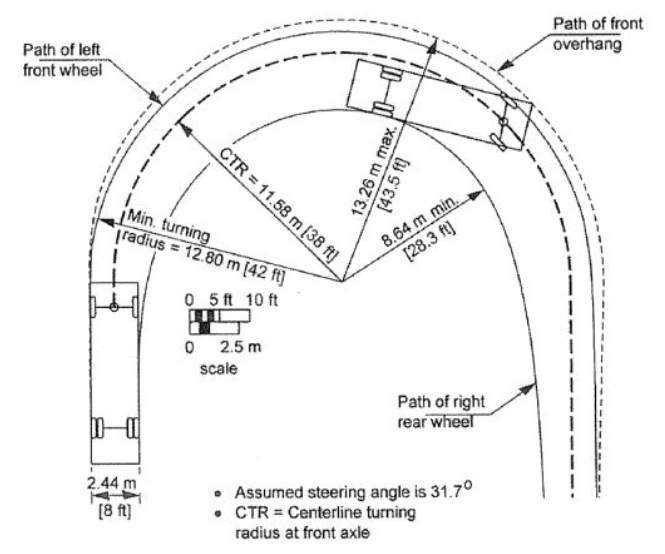

Figure 3 - The swept path envelope of the AASHTO SU Vehicle

\subsection{Swept Path Analysis}

The layout drawn for the roundabout was used to model the vehicle turning simulation with the aid of the computer program, 'AUTO TURN'. This program is widely used in wellknown highway design software programs such as Auto CAD Civil 3D and Bentley Inroads. It gives a graphical representation of the vehicle path inside the roundabout. Using this graphical representation, a clear idea as to whether the roundabout is functioning properly or not can be obtained. For the swept path, following critical turns would be analysed. The swept path analysis software can also be used to identify the following parameters which may have to be improved on:

1. Straight path movement

2. U turn movement

3. Left turn movement

Using the swept path analysis, the highest possible speed for a SU; required width for circulation and the possible number of lanes; and the largest possible vehicle that can pass via the roundabout can be determined.

\section{Data Collection}

\subsection{Field Measurements}

In this study, the following main geometric parameters of each roundabout were collected through field measurements:

- Inland diameter $\left(D_{1}\right.$ and $\left.D_{2}\right)$

- Circulation width $\left(\mathrm{W}_{1}\right.$ and $\left.\mathrm{W}_{2}\right)$

- Split island width

- Split island length

Figure 4 depicts the geometric parameters collected through the field measurements of the selected roundabouts which were tabulated subsequently.

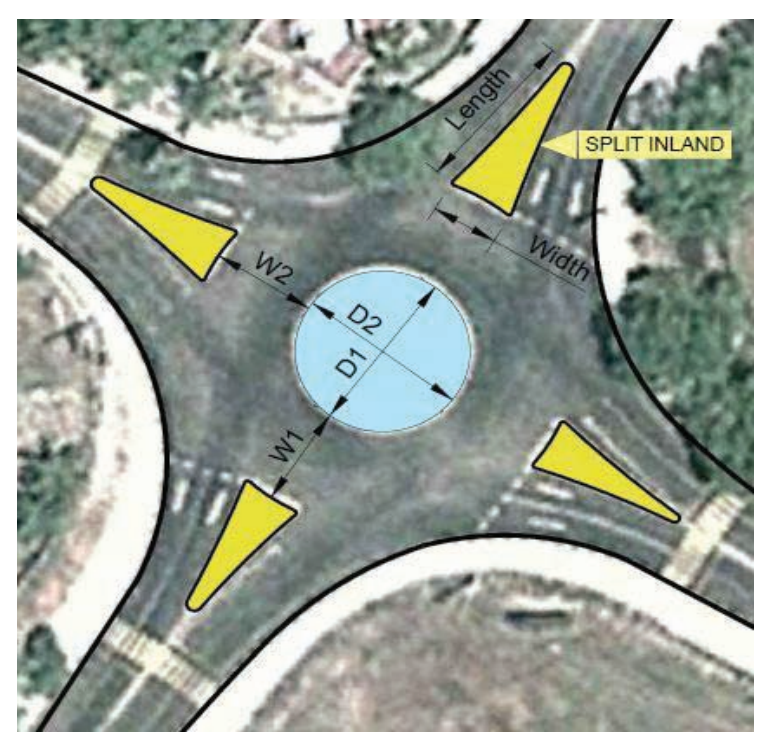

Figure 4 - Measured geometric parameters of the roundabout

\subsection{Direct Measurements and Extracted Parameters}

Satellite images were calibrated using some of the field measurements. The satellite images so calibrated were verified by checking with the other field measurements. Verified AutoCAD drawings were used to extract the following parameters: 
1. Entry width

2. Exit width

3. Entry radius

4. Exit radius

Using the roundabout layout developed, the entry angle and the approach path radius were derived.

Parameters such as the exit radius, entry radius, entry angle and approach path radius were also then derived. The layout drawn for the roundabout was used to model the vehicle turning simulation with the aid of the computer program, 'Vehicle TURN'. This software gives a graphical representation of the vehicle path inside the roundabout. Therefore, the efficiency of the roundabout and the parameters which need modifications can be identified.

\section{Analysis and the Discussion of the Results}

5.1 Comparison of the selected Parameters of the Roundabouts with those recommended in the International Guidelines Each measured, derived and extracted parameter was further analysed. The values obtained for the under mentioned parameters of the selected roundabouts were compared with those of the corresponding parameters provided in the international guidelines.

\subsubsection{Inscribed Circle Diameter - ICD}

As discussed earlier, the inscribed circle diameter is defined as the distance across the circle inscribed by the outer curb (or edge) of the circulatory roadway. When the diameter of a roundabout is increased, it usually results in a better approach geometry which helps to reduce vehicle approach speeds. Therefore, both Oman guidelines and DMRB(Design Manual for Road and Bridges)state that the minimum inscribed diameter should be $28 \mathrm{~m}$ while according to Dubai guidelines it should be $29 \mathrm{~m}$. Larger diameters will encourage higher circulating speeds and may lead to erroneous movements by making the drivers to perceive the time taken to traverse the roundabout as too long. Therefore, Austroads and AASHTO provide an optimum range for the ICD. According to Austroads, this optimum range is between 25-37 m, while AASHTO recommends an optimum range between $25-30 \mathrm{~m}$. Figure 5 illustrates the measured inscribed circle diameter values (excluding ellipsoidal RA)of the selected roundabouts and the diameters recommended in the guidelines. From Figure 5, it can be observed that the largest inscribed circle diameter of $60 \mathrm{~m}$ is in the NelumPokuna roundabout (CO-04) in Colombo. The next two largest values are in the Provincial Council roundabout (AN-06) and JayanthiVihara (AN01) roundabout in Anuradhapura being $41 \mathrm{~m}$ and $40 \mathrm{~m}$ respectively. The smallest inscribed circle diameter of $24 \mathrm{~m}$ was found in the Galle Stadium roundabout (GL-01). However, it can be concluded that most of the roundabouts considered in this study comply with the requirements specified in the AASHTO, DMRB, Oman and Dubai Guidelines.

\subsubsection{Central Island Diameter - CID}

The central island of a roundabout is the raised, non-traversable area encompassed by the circulatory roadway. When the central island diameter is considerably large, it will enable circulating vehicles to travel at highspeeds. According to DMRB guidelines, the minimum central island diameter is $4 \mathrm{~m}$. Austroads propose the optimum central is land to be $10 \mathrm{~m}$.

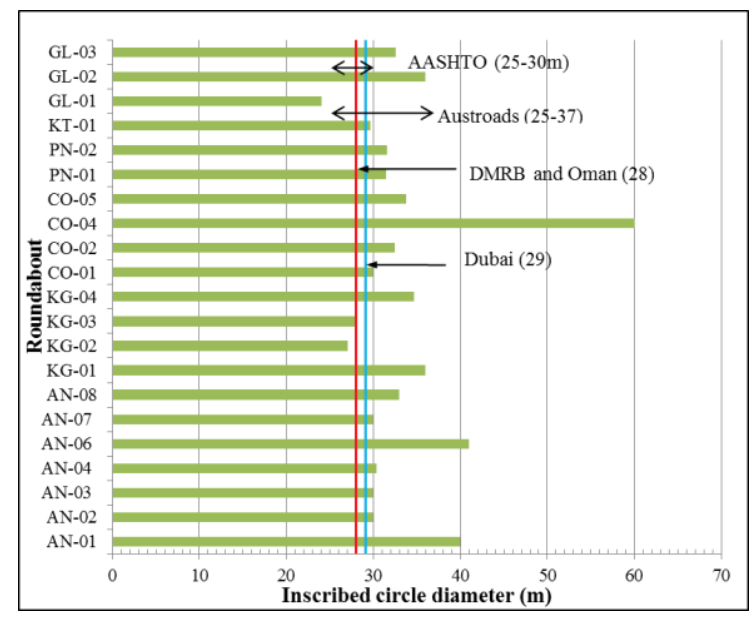

Figure 5 - Analysis of the inscribed circle diameter

Almost all of the roundabouts studied except the Borella Cemetery roundabout (CO-03) and the Galadari roundabout had circular shaped central islands. It is expected in general, the central island to be circular in shape because a circular-shaped central island with a constant radius circulatory roadway will help to promote constant speeds around the central island. Oval or irregular shapes, on the other hand, are more difficult to drive through and can promote high speeds on the straight sections and low speeds on the arcs of the oval.

Figure 6 illustrates the measured central island diameters of the selected roundabouts and the corresponding diameters recommended in the 
international guidelines. From Figure 6, it is clear that all of the selected roundabouts exceed the minimum values given for the central island diameter in the international guidelines. The smallest and the most critical value of $5.9 \mathrm{~m}$ is in the Kalutara Church roundabout whereas the largest central island diameter of $38.5 \mathrm{~m}$ is in the Galle Face roundabout (CO-06). The next two largest diameters $24.2 \mathrm{~m}$ and $23 \mathrm{~m}$ are at the Provincial Council roundabout in Anuradhapura (AN-06) and the NelumPokuna roundabout in Colombo (CO-04).

\subsubsection{Circulation Width}

The required width of the circulatory roadway is determined by the width of the entries and the turning requirements of the design vehicle. According to Austroads guidelines, the minimum circulation width can be identified as 7.6m. AASTO, DMRB, Oman and Dubai guidelines stipulate a minimum circulation width equal to (1-1.2) x maximum entry width. Figure 7 illustrates the measured circulation widths of the selected roundabouts and the corresponding widths recommended in the international guidelines.

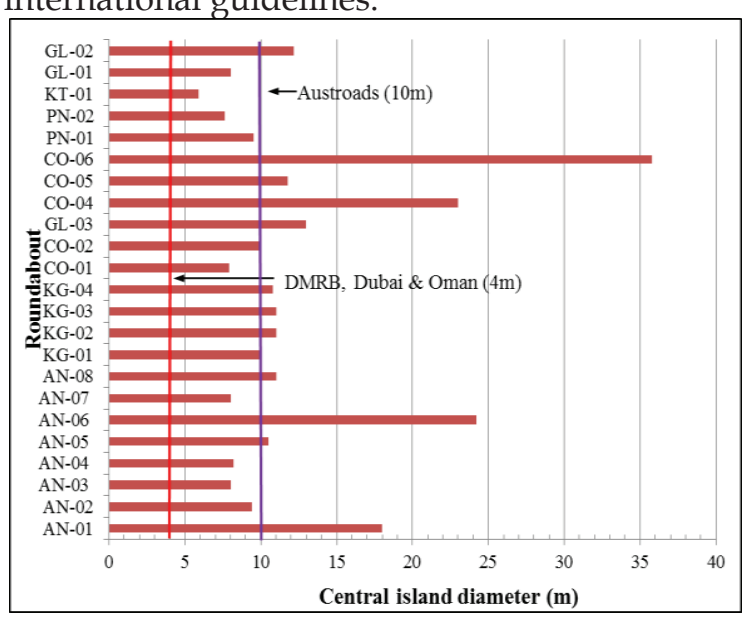

Figure 6 - Analysis of the central island

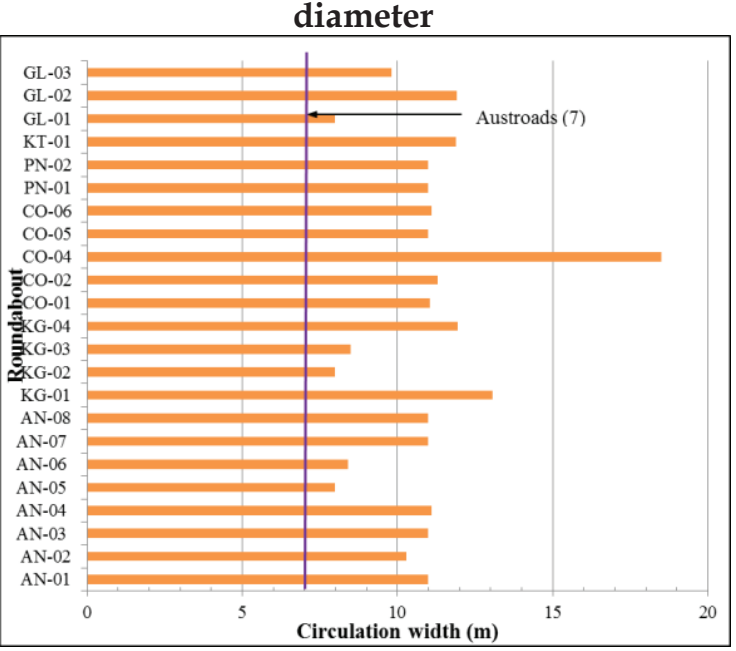

Figure 7 - Analysis of the circulation width
From Figure 7, it is clear that all of the selected roundabouts comply with the minimum criteria for the circulation width $(7.6 \mathrm{~m})$ specified in Austroads guidelines. The lowest and the most critical value of $8.0 \mathrm{~m}$ is reported in the Kadurug as Junction roundabout in Kurunegala (KG-02) and the Bank Town roundabout in Anuradhapura (AN-05). The highest circulation width of $38.5 \mathrm{~m}$ is in the NelumPokuna roundabout (CO-04). Most of the roundabouts have circulation widths between 10 mto12 m. Figure 7 illustrates the measured circulation widths of the selected roundabouts comparing them with values given in DMRB, and Oman and Dubai guidelines. The critical circulation width has been considered as the maximum entry width.

According to the study, it is clear that most of the selected roundabouts comply with the requirements set out in AASHTO, DMRB and Dubai and Oman Guidelines except the Bank Town roundabout at Anuradhapura (AN-05) and the Galle Face roundabout (CO-06) in Colombo. However, in each of these two roundabouts also, the circulation width has been set at the critical circulation width.

\subsubsection{Entry Radius}

The entry radius is one of the most critical geometrical parameters of a roundabout contributing considerably to its functionality. It will determine how efficiently traffic is circulated around the roundabout and the amount of space taken up by the roundabout. When the entry radius is decreased, it usually enables a better approach geometry leading to a reduction in the approach vehicle speeds. Both Oman and DMRB guidelines recommend the minimum entry radius to be $10 \mathrm{~m}$ while Dubai guidelines recommend it to be at a minimum of $6 \mathrm{~m}$ or $10 \mathrm{~m}$ with an optimum value of 20m. AASHTO, DMRB and Omanguidelines provide a range for the entry radius. According to Austroads, this optimum range is between $10 \mathrm{~m}$ and $100 \mathrm{~m}$.

Figure 8 illustrates the entry radii of the selected roundabouts comparing them with the corresponding radii given in the above mentioned guidelines which are between $6 \mathrm{~m}$ to $100 \mathrm{~m}$. From the results of the study, it can be concluded that most of the selected roundabouts comply with the requirements set out in the international guidelines. However, the minimum entry radii of the roundabouts at EgodaUyana,
PanaduraGldenStatue, 
Dhaiyagama Junction and Isurumuniya Junction exceed these recommended values.

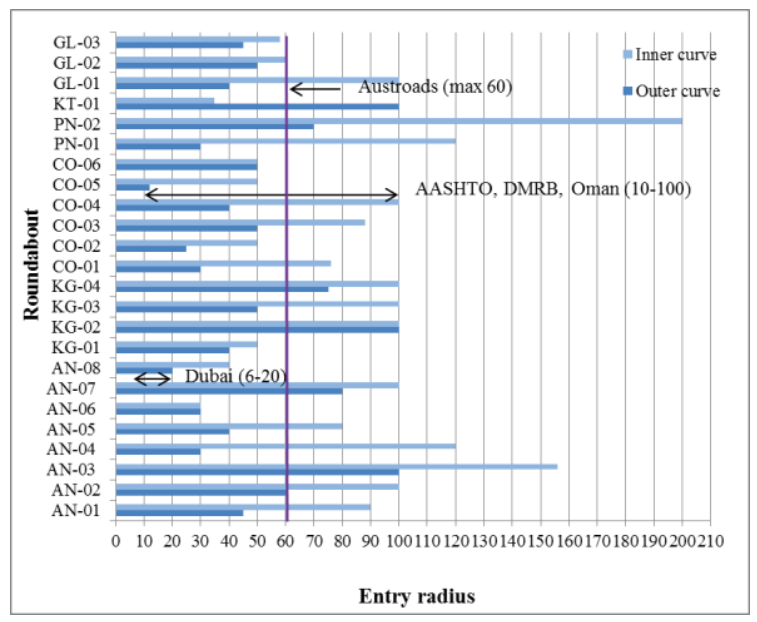

Figure 8 - Analysis of the entry radius

\subsubsection{Exit Radius}

The exit radius is one of the factors that contributes to the efficiency of aroundabout. A higher exit radius would facilitate a better outflow from the roundabout. Therefore, the exit radius selected was what has been recommended in the guidelines. The Dubai and DMRB guidelines specify a range for the exit radius. The Dubai guidelines state that it should be within $20 \mathrm{~m}$ to $200 \mathrm{~m}$ with an optimum value of $40 \mathrm{~m}$. A higher exit radius will encourage higher outflow speeds and may result in an efficient roundabout. Therefore, Austroads and AASHTO recommend that the exit radius should be as straight as possible. The AASHTO guidelines specify a minimum value of $15 \mathrm{~m}$ for the exit radius. On the other hand, the Oman guidelines recommend the exit radius to be equal or more than the entry radius. Figure 9 illustrates the exit radii of the selected roundabouts obtained from measurements and the values recommended for them in the international guidelines.

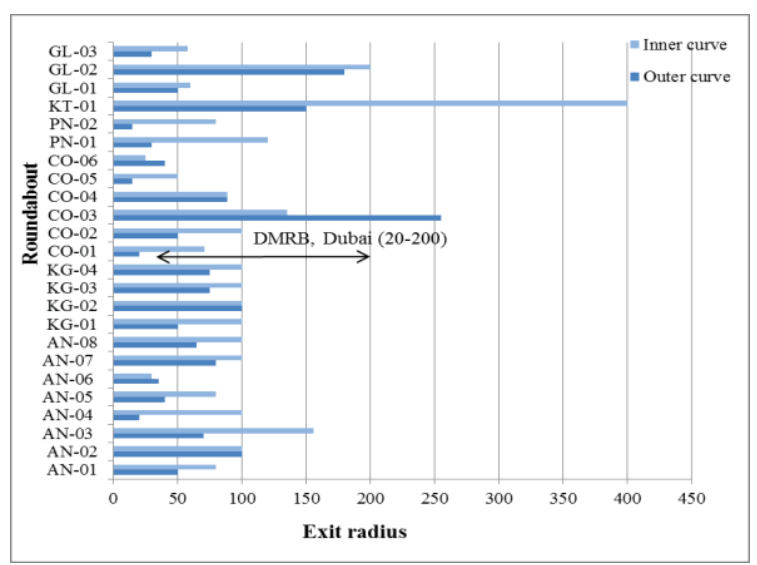

Figure 9 - Analysis of the exit radii
According to international guidelines, the exit radius should not be less than $15 \mathrm{~m}$. From the results, it can be identified that most of the selected roundabouts except the Lipton and Golden Statue roundabouts comply with the requirements set out in those guidelines. The exit radii of the Lipton and Golden Statue roundabouts are $89 \mathrm{~m}$ and $15 \mathrm{~m}$ respectively.

\subsubsection{Approach Path Radius}

The approach path radius is very important for roundabout action. According to Austroads guidelines, the optimum approach path radius is $100 \mathrm{~m}$. In this study, the approach path radius was obtained for each roundabout as the maximum approach path radius bring quite critical for roundabout action.

It is clear that in many of the roundabouts (16 roundabouts), the approach path radii are very much more than the values recommended in the international guidelines. It is important to maintain the optimum approach path radius to lower the approach speed. Only the Anuradhapura Provincial Council roundabout (AN-06) has an approach path radius of $113.7 \mathrm{~m}$ which is very much close to the optimum value recommended in the international guidelines.

\subsubsection{Entry Angle}

The entry angle is a geometric proxy for the conflict angle between the entering and circulating streams. In order to overcome the complexity of data representation, only the maximum and minimum entry angles were selected in this study for further analysis. According to DMRB, Dubai and Oman guidelines, the entry angle should be between $20^{\circ}-60^{\circ}$ and according to Dubai guidelines the optimum entry angle is $30^{\circ}$. It can be concluded that most of the selected roundabouts comply with the international guidelines. However the Isurumuniya Junction roundabout at Anuradhapura (AN-03), Kadurugas Junction roundabout in Kurunegala (KG-02) and Golden Statue roundabout in Panadura (PN-02) have small entry angles.

\subsection{Swept Path Analysis}

A swept path analysis calculates and analyses the movement and the path of a vehicle when it is undertaking a turning manoeuvre. At a basic level, this includes the calculation of the path taken by each wheel during the turn and also the calculation of the space needed by the vehicle body during the turn. Although this form of calculation was initially carried out manually, in the recent years software 
developed for this purpose has been used for the calculation. Some of the swept path analysis programs available in the industry are Auto TURN, Auto Track and Vehicle TURN. In this study, Vehicle TURN program was for the swept path analysis.

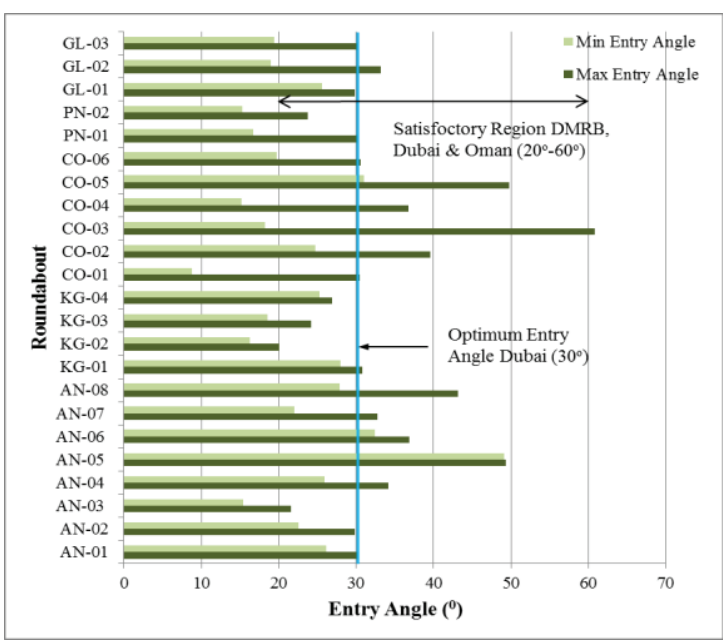

Figure 10 - Analysis of Entry Angle

The swept path analysis results show that the Borella Cemetery roundabout (Colombo-08) and the Galadari roundabout (Colombo-1)have minimum SU speeds of $2.1 \mathrm{kmph}$ and $3.5 \mathrm{kmph}$ respectively through the inner lane with an average speed of the SU (Single Unit Truck) through the inner lane at $7.6 \mathrm{kmph}$ and 9.5 $\mathrm{kmph}$ respectively. Figure 11 illustrates the required circulation width and the available circulation width of each roundabout. It can be concluded that all the roundabouts except the Bank Town roundabout (AN-05) and the Vidyaloka roundabout (GL-01) have satisfactory circulation widths. Both the Bank Town roundabout (AN-05) and the Vidyaloka roundabout (GL-01) has a circulation width of $8 \mathrm{~m}$ each.

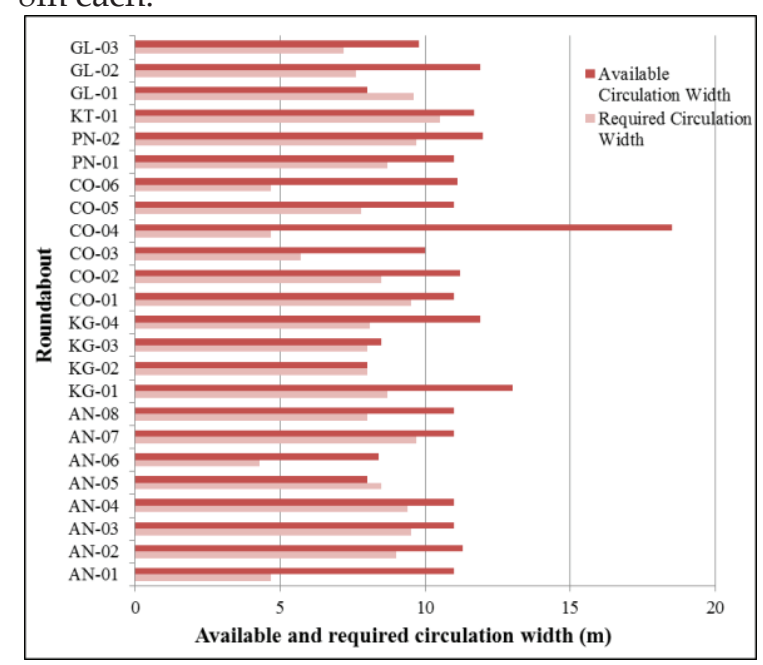

Figure 11 - Comparison of available circulation widths and the required circulation widths based on the outcome of the swept path analysis

\section{3}

\section{Development of a Roundabout} Guideline for Sri Lanka

Many of the parameters of the selected roundabouts were in line with the values given in the international guidelines. The parameters of the selected roundabouts are shown in Table 2.

Table 2 - Comparison of the roundabout parameters of Sri Lanka with those given in international guidelines

\begin{tabular}{|c|c|c|c|c|c|c|}
\hline Roundabout & AustRoad & AASHTO & DMRB & DUBAI & OMAN & Sri Lanka \\
\hline $\begin{array}{c}\text { Inscribed } \\
\text { Circle } \\
\text { Diameter, m }\end{array}$ & $25-37$ & $25-30$ & $\begin{array}{c}\min \\
28\end{array}$ & $\min 29$ & $\min 28$ & Complied \\
\hline \begin{tabular}{|c|} 
Centre \\
Island \\
Diameter, \\
$\mathrm{m}$ \\
\end{tabular} & 10 & $\begin{array}{l}\text { based on } \\
\text { design } \\
\text { vehicle }\end{array}$ & $\min 4$ & $\min 4$ & $\min 4$ & Complied \\
\hline $\begin{array}{l}\text { Carriageway } \\
\text { Width single } \\
\text { Lane, m }\end{array}$ & 7.6 & $\begin{array}{l}(1-1.2)^{*} \\
\max E W\end{array}$ & $\begin{array}{l}(1- \\
1.2)^{*} \\
\max \\
\text { EW }\end{array}$ & $\begin{array}{c}(1-1.2)^{*} \\
\max E W\end{array}$ & $\begin{array}{l}(1-1.2)^{*} \\
\text { maxEW }\end{array}$ & Complied \\
\hline $\begin{array}{c}\text { Entry } \\
\text { Radius, m }\end{array}$ & 60 & $10-30$ & $20-100$ & 20 & $20-100$ & \begin{tabular}{|c|} 
Not \\
Complied
\end{tabular} \\
\hline $\begin{array}{c}\text { Exit Radius, } \\
\mathrm{m}\end{array}$ & $\begin{array}{c}\text { straight } \\
\text { as } \\
\text { possible }\end{array}$ & $\min 15$ & $15-20$ & $\begin{array}{c}40 \\
(20-200)\end{array}$ & $15-20$ & Complied \\
\hline \begin{tabular}{|c|} 
Entry width, \\
$\mathrm{m}$ \\
\end{tabular} & 5 & $\min 6$ & $3-4.5$ & $6-15$ & $3-4.5$ & Complied \\
\hline $\begin{array}{c}\text { Exit width, } \\
\mathrm{m}\end{array}$ & 5 & $\begin{array}{c}\text { based on } \\
\text { exit } \\
\text { curve R }\end{array}$ & $7-7.5$ & 7.3 & $7-7.5$ & Complied \\
\hline $\begin{array}{c}\text { Entry Angle, } \\
\text { degree }\end{array}$ & - & - & $20-60$ & $\begin{array}{c}20-60(30 \\
\text { optimum) }\end{array}$ & $20-60$ & $\begin{array}{c}\text { Not } \\
\text { Complied }\end{array}$ \\
\hline $\begin{array}{c}\text { Approach } \\
\text { path radius, } \\
\mathrm{m}\end{array}$ & 100 & 100 & 100 & 100 & 100 & \begin{tabular}{|c|} 
Not \\
Complied
\end{tabular} \\
\hline
\end{tabular}

For the proper functioning of a roundabout, the speed of an entry vehicle has to be lowered when circulating around the centre island. This requirement mainly depends on the parameters given in Table 2(entry radius, entry angle and approach path radius) which are recorded as not complying with the vales recommended in international guidelines. Hence, based on international guidelines, the following values can be recommended for Sri Lanka:
- Entry radius
$-20 m-60 m$
- Entry angle
$-20^{\circ}-60^{\circ}$
- Approach path radius - $100 \mathrm{~m}$

\section{Conclusions and Recommendations}

Roundabouts provide solutions for intersections having capacity/delay issues, intersections for which traffic signals have been requested but not warranted etc. Well-designed 
roundabouts have proven to be safe and efficient forms of intersection control. In Sri Lanka, roundabouts are frequently used in urban areas such as Colombo, Gampaha, Anuradhapura and Galle that have heavy traffic. However, the roundabout geometric design is new to Sri Lanka. Hence, it has become a timely requirement to identify the parameters that need to be improved on in the existing roundabouts and the factors that need to be considered in developing a design guideline for Sri Lanka.

Considering the results of the parameter analysis and swept path analysis, it can be concluded that the sizes of almost all (96\%) roundabouts are within the minimum range stipulated in the international guidelines (ICD).Except for a few, the centre island diameter $(100 \%)$, circulation width $(92 \%)$, and exit radius $(92 \%)$ of most of the roundabouts are near the upper end of the minimum range stated in the international guidelines.

However, entry radii are found to be higher than the values recommended in international guidelines. Only 13\% of the selected RAs were within the range of the entry angles stated in the international guidelines. Many of the roundabout approach path radii are very much higher than $100 \mathrm{~m}$, the value recommended in the international guidelines. This can lead to serious safety issues when the roundabout is operating at a lower speed. (Approach path speed is more than the circulation speed of the roundabout) The approach speed should be lowered through geometric design reducing the entry radius and the approach path radius. According to swept path analysis results, two of the RAs out of the twenty four selected are not satisfying the requirement for the ICD and hence the circulation width. This was confirmed by parameter analysis results as well. Also it can be concluded that circular roundabouts are more likely to function efficiently than ellipsoidal roundabouts.

\subsection{Recommendations}

The following recommendations can be made based on the study results:

- To go by the guidelines provided for entry radius, entry angle and approach path deflection radius in order to improve the geometry of the RA as roundabout is operating at lower speed

- To have a higher value for the exit radius than for the entry radius.
- To have a circular central island as it will be more effective than an ellipsoidal central island

- To identify locations which can accommodate a satisfactory geometric design

- To consider interconnected signals system as an alternative, as it will provide a better level of service.

\section{References}

1. Ren, L., Qu, X., Wang, S. \& Guan, H. (2014). Investigation on entry capacities of singlelane roundabouts. Applied Mechanics and Materials, 505-506, 497-500.

2. Wiki, Roundabouts, 17 July 2015, Available from:

$<$ https://en.wikipedia.org/wiki/Roundabo ut>. [3 August 2015].

3. Douglas, C., 2011, Traffic Control At The Intersection Of Muskoka Road 42 (Taylor Road) And Cedar Lane In The Town Of Bracebridge, The district municipality of Muskoka, Engineering and public works department.

State of Maryland department of transportation state, 1995, high way administration roundabout design guidelines.

4. United States Department of Transportation (US DOT), Roundabouts: An informational guide, USA, 2001, pp 145-165.

5. Austroads 2007, Guide to traffic management: part 6: intersections, interchanges and crossings,AGTM06/07, Austroads, Sydney, NSW.

6. Geometric design for Dubai roads, Dubai, 2002, pp 12-24. 